\title{
Effect of parasitized prey on prey consumption, survival, growth, and development of Coccinella septempunctata L. (Coleoptera: Coccinellidae) under laboratory conditions
}

\author{
Ahmad Manan Mustafa Chatha ${ }^{*^{*}}$ (i) and Saima $\mathrm{Naz}^{2}$ (i)
}

\begin{abstract}
A study of interactions among natural enemies is important to develop a better biological control program. Among these interactions, one that is crucial is the consumption of parasitized prey by a predator. Feeding on aphid mummies could affect the predator as well as the parasitoid species. In this study, the effect of parasitized prey on prey consumption, survival, growth, and development of 4th instar larvae of the predatory species, Coccinella septempunctata L. (Coleoptera: Coccinellidae), as an active predator of aphids, was studied. Moreover, the effect of parasitized and mummified aphids on female fecundity was also evaluated. The green peach aphid, Myzus persicae Sulzer (Hemiptera: Aphididae) was used. Obtained results showed that the parasitized aphids, as a predatory food, significantly affected the predator. The prey consumption was highest on parasitized $(24.10 \pm 0.53)$ and lowest on mummified $(9.75 \pm 0.40)$ aphids. The survival rate was in the order of non-parasitized $>$ parasitized $>$ mummified. The mass gained by the 4 th instar larvae of $C$. septempunctata was in the order of parasitized $(26.25 \mathrm{mg} \pm 0.89)>$ non-parasitized $(19.25 \mathrm{mg} \pm 0.86)>$ mummified aphids (10.20 mg \pm 0.52 ), when fed on different prey. Developmental time of the predator was recorded highest, when it consumed mummified aphids (13.6 \pm 0.39 ). As well, female fecundity was affected positively. The female was observed to lay the most eggs $(323.55 \pm 1.57)$ to have the highest number of hatched eggs $(38.70 \pm 0.92)$, and to have the highest egg mass (196.10 $\mu \mathrm{g} \pm 1.22$ ), when it consumed the parasitized aphids in contrast to non-parasitized and mummified aphids. It was also found that the type of prey did not affect the incubation period of the eggs.
\end{abstract}

Keywords: Foraging behavior, Aphid mummies, Parasitized prey, Coccinella septempunctata, Intraguild predation

\section{Background}

Extensive use of pesticides adversely affects the population of biological control agents in the field and green house crops (Tooker et al. 2020). As a result, the potential control that they can provide is also restricted, which may result in the outbreaks of different pest species decreasing

\footnotetext{
* Correspondence: manan.chatha@iub.edu.pk

'Department of Entomology, University College of Agriculture and Environmental Sciences, Baghdad-ul-Jadeed Campus, The Islamia University of Bahawalpur, Hasilpur Road Bahawalpur, Punjab 36100, Pakistan Full list of author information is available at the end of the article
}

the crop yield (Douglas et al. 2015). Furthermore, resistance to different pesticides has been documented in many pest species like the aphid species, Myzus persicae Sulz. (Hemiptera: Aphididae) (Voudouris et al. 2017). In order to reduce the pest population and enhance the environmental safety effectively, Integrated Pest Management (IPM) including biological control, is the most appropriate strategy (Jalali et al. 2009; Skouras et al. 2017).

One of the advantages of predatory insects is their ability to feed on a range of non-preferred prey species, when their preferred prey is scarce. However, the ability 
of predators to feed on multiple prey species can sometimes create an intraguild competition among different biological control agents. One of these competitions is feeding on parasitized prey, which may reduce the biological control of the target pest species. There is a very little understanding of the effects of consumption of parasitized prey on predator's fitness as well as on the overall biological control program. Thus, exploring the predatory behavior of an insect predator on parasitized prey is useful for understanding its effects on predator's growth and development.

The green peach aphid, Myzus persicae Sulz. is a polyphagous aphid species that can be found worldwide attacking many crops and a widespread pest of brassica crops in the world (Blackman and Eastop 2000). This aphid was found to be an important prey for many predatory species such as lacewings and the coccinellids (Hodek and Honêk 2013). One of the major problems of M. persicae is damaging the photo-assimilates and transmits viruses, causing heavy losses of crop yield (Cao et al. 2016).

Insect predators have relatively longer life duration than parasitoids and consume a range of insects. Hence, they are indulged in the intraguild competition (Polis and Holt 1992; Rosenheim et al. 1995). Predators have shown a reduced biological control in the presence of entomoparasitoids (Fincham et al. 2019). Predators may reduce pest control by feeding on other bioagents present in the crops (Rosenheim et al. 1993; Snyder and Wise 2001). In a predator-parasitoid interaction, the predators mostly consume specialists, with a rare chance of reverse happening (Brodeur and Rosenheim 2000; Lucas et al. 1998). Thus, generalists could potentially decrease the biological control program (Snyder and Ives 2001).

To develop a better understanding of predators vs. parasitoid interactions in a biological control program, different experimental studies have been studied (Chang and Kareiva 1999). The predatory species, Coccinella septempunctata L., has a significant importance worldwide as a voracious aphidophagous predator (Soni et al. 2004). Both its larvae and adults are active aphidophagous predator. Prey scarcity and poor diet could lead towards lower developmental rate and survival (Sarwar and Saqib 2010). C. septempunctata has shown better performance than other predators as biological control agent in an intraguild predation competition (Afza et al. 2019). However, the effect of feeding a predator on parasitized prey has rarely been investigated. Several studies concluded that the quality of the aphids significantly affects the performance of ladybird beetles, especially at larval stages. Moreover, it was found that C. septempunctata is highly specific to the aphids' diet (Hodek and Honêk 2013). However, the effect of aphid mummies as a predator's diet has not well studied and understood (Takizawa et al. 2000).
The present study aimed to evaluate the effects of parasitized prey on development, survival, prey preference, and fecundity of C. septempunctata.

\section{Materials and methods \\ Plant and insect cultures}

Cabbage, Brassica oleracea L. (Brassicaceae) plants, were used to rear the predator (C. septempunctata) and the prey species $(M$. persicae). The plants were grown in beds and later transplanted in pots (100 mm radius) to provide them to insect culture. The cabbage plants were raised in an insecticidal-free environment and under natural light in a wired house, watering the plants daily or every other day depending upon the weather conditions.

\section{The aphid, Myzus persicae}

$M$. persicae culture was established by collecting the aphids from a cabbage field close to the Multan Road, Bahawalpur, Punjab, Pakistan. Collected aphids were screened for any chance of being parasitized for 3 days. After the 3 days, healthy aphids were shifted into cages $(2 \times 2 \times 2.5 \mathrm{ft})$ and reared on cabbage at the entomology laboratory, UCA\&ES, the Islamia University of Bahawalpur Punjab, Pakistan. The cages were placed under the laboratory conditions at $25 \pm 2{ }^{\circ} \mathrm{C}, 55-65 \%$ R.H. and artificial lighting. Cages were kept close to the window to provide natural light when possible. Plants were replaced with new ones when necessary.

\section{The predator, Coccinella septempunctata}

Adults of C. septempunctata were obtained from a cabbage field near Multan Road Bahawalpur, Punjab, Pakistan, and were reared at the entomology laboratory, UCA\&ES, the Islamia University of Bahawalpur Punjab, Pakistan. The predator was reared on $M$. persicae in a cage $(2 \times 2 \times 2.5 \mathrm{ft})$ up to the 4 th instar larvae. Water was also provided in cages with a wet cotton wick. The 4th instar larvae were used in experiments of prey consumption, survival, growth, and development, while adult females were used for the test of fecundity. A couple of adult C. septempunctata were selected for oviposition and kept into the separate petri dishes to get the uniform aged batches of eggs for the experiments.

\section{Experimental design}

Effects of parasitized prey on prey consumption, survival, growth, and development as well as female fecundity of C. septempunctata under laboratory conditions were studied. Three types of prey (healthy (non-parasitized), parasitized (1 day-old parasitized), and mummified (aphid mummies) were tested. Small plastic container (120 $\mathrm{mm}$ diameter, $80 \mathrm{~mm}$ height) with holes in the lid for proper aeration was used to conduct the experiments. Each plastic container was provided by 30 early 
4th instar nymphs of either non-parasitized, parasitized, or mummies of $M$. persicae placed on a cabbage leaf. A control treatment was not used in this experiment since preliminary tests showed more than $92 \%$ survival of the predator. Twenty-four hours starved and 1-day-old 4th instar larvae of $C$. septempunctata were used for the experiments. Same day egg batch was used to obtain a uniform population of 4th instar larvae of C. septempunctata. Aphid mummies collected from the cabbage field were allowed to complete their development until emerging as parasitoid adults and then they were allowed to sting healthy aphid's nymphs in a cage $(2 \times 2$ $\times 2.5 \mathrm{ft}$ ). These newly parasitized aphids and aphid mummies were used in the experiments along with healthy aphids. The predators were placed singly in a petri dish to starve for about $24 \mathrm{~h}$ before the experiment. Each predator was tested only once. Each experiment was tested for exactly every $24 \mathrm{~h}$ at artificial lighting with 14L: 10D photoperiod and $25 \pm 2{ }^{\circ} \mathrm{C}$.

Twenty replicates were performed for each experiment. Prey consumption was recorded by counting the remaining aphid and aphid mummies after each experiment. Survival of C. septempunctata was considered successful when larvae developed to adults. The percentage of survived predators was calculated. The development of the predator was tested by subtracting the mass of each predator at the newly developed pupal stage from the mass at the start of the 4th instar larvae. Developmental time was recorded from newly molted 4th instar larvae to the development of adults in days. For the experiment of fecundity, adult couples of males and females were kept in a petri dish separately. The healthy, parasitized, or mummified prey were provided by a cabbage leaf as a substrate for egg-laying. The numbers of eggs laid were counted daily and a new leaf was provided as well. The trial was ended when no new eggs were laid at the end of the 24-h period. Total eggs laid were counted and 50 of these eggs were kept for further recording of the incubation period. Ten eggs were selected randomly from each treatment and weighed together and then the average egg mass per female was estimated.

\section{Data analysis}

PASW Statistics 18 (release 18.0.0) was used for data analyses of different biological and reproductive parameters. The significance level was tested by one-way ANOVA at $p<0.05$ and Duncan's multiple range test was used for the comparison of the data. The homogeneity of variances test was also performed to confirm that the assumptions for ANOVA are met in the analysis. Graphs were constructed in Microsoft Excel. The survival rate (\%) of the predator was tested, using the chisquare test with $p<0.05$.

\section{Results and discussion \\ Effect of feeding C. septempunctata on parasitized aphids Biological parameters}

Average values of the effect of feeding C. septempunctata on parasitized prey on different biological parameters of the C. septempunctata are given in Table 1 . The prey consumption by $C$. septempunctata on different prey types was in the order of parasitized > nonparasitized $>$ mummified aphids. The consumption of parasitized prey was the highest $(24.10 \pm 0.53)$ followed by non-parasitized $(22.65 \pm 0.50)$, while the mummified aphids $(9.75 \pm 0.40)$ were the least for the predator. The consumption of each prey type was significantly different $(p \leq 0.05)$ from the others.

The growth (mass gained) of 4th instar larvae was analyzed by considering the mass gain from the start of the 4th larval instar to the start of the pupal stage of the predator. Growth of 4th instar larvae of C. septempunctata was significantly different $(p \leq 0.00)$ among different prey types and was in the order of parasitized $>$ nonparasitized $>$ mummified aphids. The highest mass gain $(\mathrm{mg} \pm$ S.E) was observed in the parasitized prey $(26.25 \pm$ $0.89)$, followed by non-parasitized $(19.25 \pm 0.86)$ and then mummified (10.20 \pm 0.52$)$ aphid prey, respectively.

Aphidophagous generalists such as C. septempunctata, as well as different aphid parasitoids commonly played a significant role of suppressing aphids' population in different agro-ecosystems (Bilu and Coll 2007). However, these predators and parasitoids do not necessarily interact in a synergistic manner (Gontijo et al. 2015). Many of these aphidophagous generalists can also consume aphid parasitoids (Chacon and Heimpel 2010).

Obtained results showed that the diet containing aphid mummies was not preferred for the 4th instar larvae of C. septempunctata. The prey consumption was greatly reduced by using aphid mummies. These findings are coherent with Takizawa et al. (2000) who concluded that the prey consumption of C. septempunctata was significantly lower when fed on aphid mummies. Fu et al. (2017b) reported the same results in case of the coccinellid, Harmonia axyridis, when fed on un-parasitized and mummified M. persicae.

This study showed that parasitized aphids were preferred over non-parasitized ones. This could be due to the reduced defense and increased vulnerability of the affected aphids. Similar results were demonstrated in case of Myrmedonota xipe Mathis \& Eldredge, beetles which consumed more parasitized ants than nonparasitized ones (Mathis and Tsutsui 2016). Another study on the predatory behavior of Callinectes sapidus, showed an around 20\% increase in prey consumption when fed with parasitized prey as compared to the healthy prey (Gehman and Byers 2017). The results are coherent with Pirzadfard et al. (2020), who concluded 
Table 1 Effect of feeding on parasitized, non-parasitized, and mummified aphids on the C. septempunctata biological parameters (mean \pm S.E)

\begin{tabular}{|c|c|c|c|}
\hline \multirow[t]{2}{*}{ Prey type } & \multicolumn{3}{|l|}{ Biological parameters } \\
\hline & No. of prey consumed & Mass gained $(\mathrm{mg})$ & Developmental time (no. of days) \\
\hline Non-parasitized aphids & $22.65 \pm 0.50^{\mathrm{bt}}$ & $19.25 \pm 0.86^{b}$ & $12.15 \pm 0.34^{b}$ \\
\hline Parasitized aphids & $24.10 \pm 0.53^{\mathrm{a}}$ & $26.25 \pm 0.89^{a}$ & $12.55 \pm 0.35^{b}$ \\
\hline Aphid mummies & $9.75 \pm 0.40^{c}$ & $10.20 \pm 0.52^{c}$ & $13.6 \pm 0.39^{a}$ \\
\hline
\end{tabular}

†Means ( \pm standard error of means) followed by different letters $(a, b$, and $c)$ in the same column are significantly different according to Duncan's multiply range test $(p<0.05)$

that while Orius albidipennis (Reuter) actively consumed both the parasitized and non-parasitized prey, a preference was observed for the parasitized nymphs of Bemisia tabaci (Genn.) over healthy ones. The obtained data is also well aligned with $\mathrm{Fu}$ et al. (2017a), who observed a $36 \%$ rejection rates for mummified prey in contrast to $2 \%$ rejection of healthy prey by $H$. axyridis.

In terms of developmental time (days \pm S.E), nonsignificant difference was recorded among parasitized (12.55 \pm 0.35$)$ and non-parasitized (12.15 \pm 0.34$)$ aphids. However, predator's developmental time on aphid mummies $(13.6 \pm 0.39)$ was significantly longer than other prey types. Overall a significant effect $(p \leq 0.00)$ of prey type was observed on developmental time of 4th instar larvae of C. septempunctata.

Many studies concluded that the nutritional deficiency of low-quality aphids (like aphid mummies) could not be replenished by mixing a good quality diet with poor diet (Nielsen et al. 2002). This study also demonstrated that overall aphid mummies were a low-quality diet and longer developmental time was observed on mummified aphid diet. Yu et al. (2020) reported that the larval developmental time of $H$. axyridis was significantly prolonged when fed with mummified prey.

Obtained results showed that the survival of C. septempunctata was significantly higher when fed on nonparasitized aphids, followed by parasitized aphids, while feeding on aphid mummies greatly reduced its survival (Fig. 1). Chi-square $\left(\chi^{2}\right)$ test showed that the survival rate (\%) of 4th instar larvae of C. septempunctata was significantly affected $(p \leq 0.037)$ by the prey type. The present study also showed that the survival rate of $C$. septempunctata decreased when it fed on parasitized and mummified aphid. In a similar study conducted on C. septempunctata but different aphid species, the survival rate of the predator was significantly affected by the diet containing aphid mummies (Takizawa et al. 2000). Agarwala and Dixon (1992) also concluded that the low-quality prey (like aphid mummies) could lead to a poor larval performance and even death before reaching the adult stage. Sugiura and Takada (1998) reported similar results and showed that poor prey quality could lead to a lower survival rate, growth, and development of other coccinellids. Obtained results are in coherent

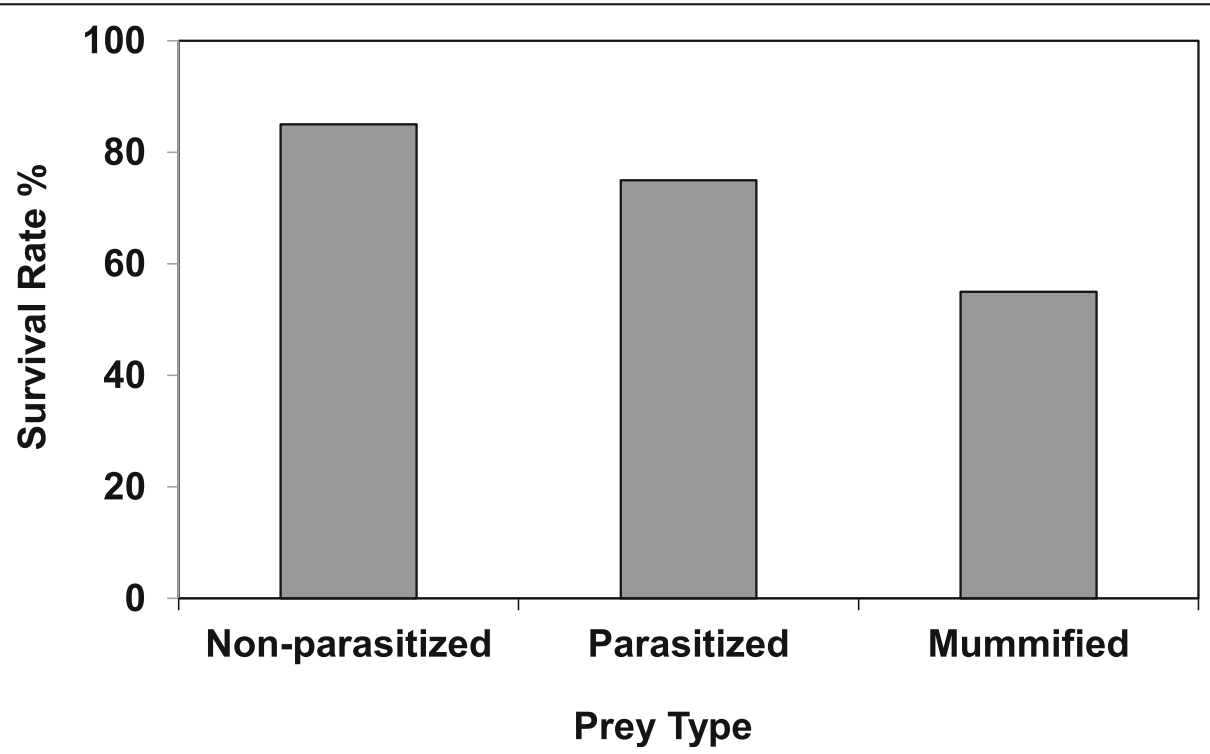

Fig. 1 Survival rate (\%) of 4 th instar larvae of C. septempunctata on non-parasitized $(n=20)$, parasitized $(n=20)$, and mummified $(n=20)$ aphids. $X$-axis represents type of the prey offered, while $Y$-axis shows the survival rate (\%) of 4th instar larvae of C. septempunctata $\left(X^{2}\right.$ test, $\left.p \leq 0.037\right)$ 
Table 2 Effect of feeding on parasitized, non-parasitized, and mummified aphids on the C. septempunctata reproductive parameters (mean \pm S.E)

\begin{tabular}{lllll}
\hline Prey type & \multicolumn{3}{l}{ Reproductive parameters } & \\
\cline { 2 - 5 } & No. of eggs laid & No. of eggs hatched & Incubation duration (no. of days) & Egg mass ( $\mu \mathrm{g})$ \\
\hline Non-parasitized aphids & $295.90 \pm 1.61^{\mathrm{c}}$ & $24.85 \pm 0.61^{\mathrm{c}}$ & $3.00 \pm 0.10^{\mathrm{a}}$ & $187.05 \pm 1.26^{\mathrm{b}}$ \\
Parasitized aphids & $323.55 \pm 1.57^{\mathrm{a}}$ & $38.70 \pm 0.92^{\mathrm{a}}$ & $3.20 \pm 0.09^{\mathrm{a}}$ & $196.10 \pm 1.22^{\mathrm{a}}$ \\
Aphid mummies & $314.85 \pm 1.04^{\mathrm{b}}$ & $31.10 \pm 0.54^{\mathrm{b}}$ & $3.35 \pm 0.10^{\mathrm{a}}$ & $195.60 \pm 1.03^{\mathrm{a}}$ \\
\hline
\end{tabular}

†Means ( \pm standard error of means) followed by different letters ( $a, b$, and $c)$ in the same column are significantly different according to Duncan's multiply range test $(p<0.05)$

with Fu et al. (2017b) who concluded that by feeding on aphid mummies, the survival rate and development of coccinellids were significantly affected. Similarly, in another study, $13 \%$ decrease in the predator survival rate was observed, when fed on infected prey (Flick et al. 2016). In contrast, 1st and 3rd instars of the lacewing, Chrysoperla rufilabris (Burr.) showed non-significant difference in its survival, when fed on healthy vs. parasitized prey (Jessie et al. 2019).

\section{Reproductive parameters}

Experiments on the fecundity of C. septempunctata females were carried to find out the total number of eggs laid by the female, the number of hatched eggs, the incubation period of eggs, and egg mass when the predator was fed either on non-parasitized, parasitized, or mummified aphids (Table 2). The total number of eggs laid by $C$. septempunctata on different prey types was in the order of parasitized > mummified > non-parasitized aphids. The number of eggs laid by feeding on parasitized aphids was the highest $(323.55 \pm 1.57)$, followed by mummified $(314.85 \pm 1.04)$ and then non-parasitized (295.90 \pm 1.61$)$ aphids, respectively. Overall, a significant difference $(p \leq 0.05)$ was observed for the total number of eggs laid by feeding on different prey types.

Similar results were obtained for egg hatching by feeding different prey. Most of the eggs were hatched, when female C. septempunctata was fed on parasitized aphids (38.70 \pm 0.92$)$, followed by mummified ( $31.10 \pm 0.54)$ and non-parasitized $(24.85 \pm 0.61)$ aphids, respectively. However, a non-significant effect $(p>0.05)$ of prey type was recorded for hatching period of the selected eggs. Regarding the egg mass, a significant effect $(p \leq 0.05)$ was observed among different prey types. The highest egg mass ( $\mu \mathrm{g} \pm$ S.E) was found, when female C. septempunctata was fed on parasitized prey $(196.10 \pm 1.22)$, followed by aphid mummies $(195.60 \pm 1.03)$ and nonparasitized (187.05 \pm 1.26$)$ aphids.

Obtained results demonstrated that aphid mummies were more suitable for egg laying and development of eggs into adult aphids. Omkar and Srivastava (2003) concluded that female fecundity was directly affected by its diet. Similarly, Sugiura and Takada (1998) suggested that the good prey quality enhanced reproductive potential and fecundity of coccinellids. The mummified aphids were not a good diet for the developing predator, but the fecundity of adult females was enhanced by feeding on aphid mummies. This could be due to the higher nutrition present in the aphid mummies as they contain developed pupae of the parasitoids inside. In another study, conducted on egg development of the coccinellid, Hippodamia variegate, it was concluded that the egg mass and egg size and no. of hatching larvae significantly increased, when fed on parasitized in contrast to nonparasitized prey (Toosi et al. 2019).

\section{Conclusion}

The present study evidenced that aphid mummies are not a preferred diet for C. septempunctata. Mummified aphid diet greatly reduced the survival and development rate of the 4th instar larvae of the predator. In the context of biological control, the less preference of aphid mummies by the predator favored the combined use of this biological control agent with parasitoids. However, further clarifications of interaction between the coccinellids and other natural enemies are still needed.

\section{Abbreviations}

R.H.: Relative humidity; UCA\&ES: University College of Agriculture and Environmental Sciences; L: D: Light period (daylight): dark period (night); ANOVA: Analysis of variance; S.E: Standard error of mean

\section{Acknowledgements \\ The authors are thankful to the Islamia University of Bahawalpur for providing controlled environment laboratory, wired house for the rearing of} plant and insect cultures, and research facility for conduction of experiments.

\section{Authors' contributions}

AC carried out the experiments on the predatory behavior of $C$. septempunctata and analyzed the data. SN reared all plants and insects culture, designed the study, and contributed in the write-up and proofreading of the manuscript. Both authors read and approved the final manuscript.

\section{Funding}

No funding agency was involved in the study. The study was conducted on the expenses of researchers only.

Availability of data and materials

Do not wish to share. The data is not very much organized to be presented here.

Ethics approval and consent to participate Not applicable. 


\section{Consent for publication}

Not applicable

\section{Competing interests}

The authors declare that they have no competing interests.

\section{Author details}

${ }^{1}$ Department of Entomology, University College of Agriculture and Environmental Sciences, Baghdad-ul-Jadeed Campus, The Islamia University of Bahawalpur, Hasilpur Road Bahawalpur, Punjab 36100, Pakistan. ${ }^{2}$ Department of Zoology, The Government Sadiq College Women University, Bahawalpur, Pakistan.

Received: 28 February 2020 Accepted: 18 June 2020

\section{Published online: 25 June 2020}

\section{References}

Afza R, Afzal M, Majeed MZ, Riaz MA (2019) Effect of intra-guild predation and sub lethal concentrations of insecticides on the predation of coccinellids. Pakistan Journal of Zoology 51(2):611-617 https://doi.org/10.17582/journal. pjz/2019.51.2.611.617

Agarwala BK, Dixon AFG (1992) Laboratory study of cannibalism and interspecific predation in ladybirds. Ecological Entomology 17(4):303-309 https://doi.org/ 10.1111/j.1365-2311.1992.tb01062.x

Bilu E, Coll M (2007) The importance of intraguild interactions to the combined effect of a parasitoid and a predator on aphid population suppression. Biocontrol 52(6):753-763 https://doi.org/10.1007/s10526-007-9071-7

Blackman RL, Eastop VF (2000) Aphids on the world's crops: an identification and information guide. John Wiley \& Sons, Ltd.

Brodeur J, Rosenheim JA (2000) Intraguild interactions in aphid parasitoids. Entomologia Experimentalis Et Applicata 97(1):93-108 https://doi.org/10. 1046/j.1570-7458.2000.00720.x

Cao HH, Liu HR, Zhang ZF, Liu TX (2016) The green peach aphid Myzus persicae perform better on pre-infested Chinese cabbage Brassica pekinensis by enhancing host plant nutritional quality. Scientific Reports:6 https://doi.org/ 10.1038/srep21954

Chacon JM, Heimpel GE (2010) Density-dependent intraguild predation of an aphid parasitoid. Oecologia 164(1):213-220 https://doi.org/10.1007/s00442010-1611-7

Chang G, Kareiva P (1999) The case for indigenous generalists in biological control. In: In Theoretical aspects of biological control. Cambridge University Press, Cambridge

Douglas MR, Rohr JR, Tooker JF (2015) Neonicotinoid insecticide travels through a soil food chain, disrupting biological control of non-target pests and decreasing soya bean yield. Journal of Applied Ecology 52(1):250-260 https://doi.org/10.1111/1365-2664.12372

Fincham WNW, Dunn AM, Brown LE, Hesketh H, Roy HE (2019) Invasion success of a widespread invasive predator may be explained by a high predatory efficacy but may be influenced by pathogen infection. Biological Invasions 21(12):3545-3560 https://doi.org/10.1007/s10530-019-02067-W

Flick AJ, Acevedo MA, Elderd BD (2016) The negative effects of pathogeninfected prey on predators: a meta-analysis. Oikos 125(11):1554-1560 https:// doi.org/10.1111/oik.03458

Fu W, Yu X, Ahmed N, Zhang S, Liu T (2017a) Intraguild predation on the aphid parasitoid Aphelinus asychis by the ladybird Harmonia axyridis. Biocontrol 62(1):61-70 https://doi.org/10.1007/s10526-016-9774-8

Fu WY, Yu XL, Ahmed N, Zhang SZ, Liu TX (2017b) Intraguild predation on the aphid parasitoid Aphelinus asychis by the ladybird Harmonia axyridis. Biocontrol 62(1):61-70 https://doi.org/10.1007/s10526-016-9774-8

Gehman A-LM, Byers JE (2017) Non-native parasite enhances susceptibility of host to native predators. Oecologia 183(4):919-926 https://doi.org/10.1007/ s00442-016-3784-1

Gontijo LM, Beers EH, Snyder WE (2015) Complementary suppression of aphids by predators and parasitoids. Biological Control 90:83-91 https://doi.org/10 1016/j.biocontrol.2015.06.002

Hodek I, Honêk A (2013) Ecology of coccinellidae. Media, Springer Science \& Business

Jalali MA, Van Leeuwen T, Tirry L, De Clercq P (2009) Toxicity of selected insecticides to the two-spot ladybird Adalia bipunctata. Phytoparasitica 37(4): 323-326 https://doi.org/10.1007/s12600-009-0051-6
Jessie CN, Giles KL, Royer TA, Payton ME, Elliott NC, Jessie WP (2019) Suitability of Schizaphis graminum parasitized by Lysiphlebus testaceipes as intraguild prey for Chrysoperla rufilabris. Southwestern Entomologist 44(1):21-33 https://doi. org/10.3958/059.044.0103

Lucas E, Coderre D, Brodeur J (1998) Intraguild predation among aphid predators: characterization and influence of extraguild prey density. Ecology 79(3): 1084-1092. https://doi.org/10.1890/0012-9658(1998)079[1084:Ipaapc]2.0. $\mathrm{CO} ; 2$.

Mathis KA, Tsutsui ND (2016) Dead ant walking: a myrmecophilous beetle predator uses parasitoid host location cues to selectively prey on parasitized ants. Proceedings of the Royal Society B: Biological Sciences 283(1836): 20161281. https://doi.org/10.1098/rspb.2016.1281.

Nielsen FH, Hauge MS, Toft S (2002) The influence of mixed aphid diets on larval performance of Coccinella septempunctata (Col., Coccinellidae). Journal of Applied Entomology 126(4):194-197 https://doi.org/10.1046/j.1439-0418.2002.00629x

Omkar SS (2003) Influence of six aphid prey species on development and reproduction of a ladybird beetle, Coccinella septempunctata. Biocontrol 48(4):379-393 https://doi.org/10.1023/A:1024762822955

Pirzadfard S, Zandi-Sohani N, Sohrabi F, Rajabpour A (2020) Intraguild interactions of a generalist predator, Orius albidipennis, with two Bemisia tabaci parasitoids. International Journal of Tropical Insect Science. https://doi.org/10. 1007/s42690-019-00075-W

Polis GA, Holt RD (1992) Intraguild predation - the dynamics of complex trophic interactions. Trends in Ecology \& Evolution 7(5): 151-154. https://doi.org/10. 1016/0169-5347(92)90208-S

Rosenheim JA, Kaya HK, Ehler LE, Marois JJ, Jaffee BA (1995) Intraguild predation among biological-control agents: theory and evidence. Biological Control 5(3):303-335 https://doi.org/10.1006/bcon.1995.1038

Rosenheim JA, Wilhoit LR, Armer CA (1993) Influence of intraguild predation among generalist insect predators on the suppression of an herbivore population. Oecologia 96(3):439-449 https://doi.org/10.1007/Bf00317517

Sarwar M, Saqib SM (2010) Rearing of predatory seven spotted ladybird beetle Coccinella septempunctata L. (coleoptera: coccinellidae) on natural and artificial diets under laboratory conditions. Pakistan Journal of Zoology 42(1):47-51

Skouras PJ, Stathas GJ, Voudouris CC, Darras Al, Tsitsipis JA, Margaritopoulos JT (2017) Effect of synthetic insecticides on the larvae of Coccinella septempunctata from Greek populations. Phytoparasitica 45(2):165-173 https://doi.org/10.1007/s12600-017-0577-y

Snyder WE, Ives AR (2001) Generalist predators disrupt biological control by a specialist parasitoid. Ecology 82(3):705-716 https://doi.org/10.2307/2680190

Snyder WE, Wise DH (2001) Contrasting trophic cascades generated by a community of generalist predators. Ecology 82(6):1571-1583 https://doi.org/ $10.2307 / 2679801$

Soni R, Deol GS, Brar KS (2004) Feeding potential of coccinellids on mustard aphid, Lipaphis erysimi (Kalt). Insect Environment 10(1):15-16

Sugiura K, Takada H (1998) Suitability of seven aphid species as prey of Cheilomenes sexmaculata (Fabricius) (Coleoptera : Coccinellidae). Japanese Journal of Applied Entomology and Zoology 42(1):7-14 https://doi.org/10. 1303/jjaez.42.7

Takizawa T, Yasuda H, Agarwala BK (2000) Effects of parasitized aphids (Homoptera : Aphididae) as food on larval performance of three predatory ladybirds (Coleoptera : Coccinellidae). Applied Entomology and Zoology 35(4):467-472 https://doi.org/10.1303/aez.2000.467

Tooker JF, O'neal ME, Rodriguez-Saona C (2020) Balancing disturbance and conservation in agroecosystems to improve biological control. Annual Review of Entomology 65(1):81-100 https://doi.org/10.1146/annurev-ento011019-025143

Toosi M, Rasekh A, Osawa N (2019) Effects of intraguild predation on the life history traits and progeny of the ladybird beetle Hippodamia variegata. Bulletin of Insectology 72(2):161-168

Voudouris CC, Williamson MS, Skouras PJ, Kati AN, Sahinoglou AJ, Margaritopoulos JT (2017) Evolution of imidacloprid resistance in Myzus persicae in Greece and susceptibility data for spirotetramat. Pest Management Science 73(9):1804-1812 https://doi.org/10.1002/ps.4539

Yu X-L, Feng Y, Feng Z-J, Chana P, Zhu G-X, Xia P-L, Liu T-X (2020) Effects of mummy consumption on fitness and oviposition site selection on Harmonia axyridis. Insect Science n/a(n/a): 1-10. https://doi.org/10.1111/1744-7917.12724.

\section{Publisher's Note}

Springer Nature remains neutral with regard to jurisdictional claims in published maps and institutional affiliations. 